\title{
Leaving and Losing a Job After Childbearing in Italy: A Comparison Between 2005 and 2012
}

\author{
Marina Zannella ${ }^{1}$, Antonella Guarneri ${ }^{2}$ \& Cinzia Castagnaro ${ }^{2}$ \\ ${ }^{1}$ Department of Methods and Models for The Economy, the Territory and Finance (MEMOTEF), "Sapienza" University \\ of Rome, Italy \\ ${ }^{2}$ National Statistical Office (Istat), Rome, Italy \\ Correspondence: Marina Zannella, Department of Methods and Models for the Economy, the Territory and Finance \\ (MEMOTEF), Via del Castro Laurenziano 9, 00161 Rome, Italy. E-mail: marina.zannella@uniroma1.it
}

Received: July 23, 2019 Accepted: September 2, 2019 Online Published: September 16, 2019

doi:10.5539/res.v11n4p1 URL: https://doi.org/10.5539/res.v11n4p1

\begin{abstract}
This article builds on microdata from the Birth Sample Survey (BSS) carried out by Istat in 2005 and 2012 in order to analyse changes in the occupational status of mothers of young children. We aim in particular to broaden the understanding of the individual and contextual characteristics that can affect the probability of women who were employed during pregnancy of not returning to work in the two years following the child's birth. The study contributes to existing literature on mothers' employment in two main ways. First, we take into consideration the different nature voluntary or involuntary - of the motivations for not returning to work. Second, we attempt to evaluate whether the likelihood of Italian mothers to leave or lose their jobs and the factors affecting these probabilities changed between 2005 and 2012. Our results confirm human capital investments and job characteristics to be among the main determinants of women's employment continuity after childbearing. The probability of losing a job increased significantly for mothers in 2012 compared to 2005, probably as a result of the deterioration of labour market conditions during the recession years. Conversely, the probability of leaving a job was not statistically significantly related to the year; family characteristics - the presence of a couple and features of the partner's job - were key factors in women's deciding not to return to work after childbearing.
\end{abstract}

Keywords: fertility, women's employment, childbirth

\section{Introduction}

The interrelationship between fertility and women's employment has long been debated. In the years following the gender revolution, scholars saw a direct link between fertility declines in Western countries and the growth in women's labour market participation (see, among others, Brewster et al., 2000). However, starting from the end of the 1980s, a positive cross-country correlation has been observed between total fertility rates (TFRs) and levels of female labour force participation in OECD countries (e.g. Ahn \& Mira, 2002). Matysiak and Vignoli (2008) demonstrated the existence of a large variation in the relation between fertility and women's employment, with the magnitude of the work-family conflict being the greatest in conservative and, especially, in familialistic welfare regimes. Institutions and policies oriented towards the reconciliation of work and family, such as parental leave, childcare provision, and access to part-time employment are much less widespread in Southern European countries. Among European countries, Italy has among the lowest levels of both total fertility and female employment. However, the average desired number of children is still greater than two, and the positive discrepancy between desired and actual fertility is higher when compared with other European countries (Testa, 2012). Moreover, the number of housewives with children interested in working, if that were compatible with their family duties, is quite high (Micheli \& Rosina, 2006).

Juggling work and family commitments is especially difficult for mothers of young children aged two years and under. Time use literature has shown the burden of unpaid work to be heaviest for mothers of children in this age range (e.g. Anxo et al., 2011), a situation made even more difficult for Italian mothers by the lack of public childcare facilities for toddlers. According to Del Boca and colleagues (2005a), Italy's public childcare for children under three is both limited and heterogeneous. This article builds on microdata from the Birth Sample Survey carried out by Istat in 2005 and 2012 with the purpose of analysing changes in the occupational status of mothers of young children. We aim in particular to broaden the understanding of individual and contextual characteristics that can affect the probability of women who were employed during pregnancy not returning to work in the two years following the child's birth. The study 
contributes to existing literature on mothers' employment in two main ways. First, we take into consideration the different nature - voluntary or involuntary - of the motivations for not returning to work. In fact, we believe that making this distinction is essential to obtaining an in-depth understanding of the determinants of employment discontinuity of mothers. Thus, to shed light on how various factors are related to women's different reasons for not going back to work after childbearing, we estimated three separate logistic models: one for the overall probability of not returning to work, without regard to cause; another for the probability of mothers' leaving their job; and the last for the probability of mothers' losing their jobs. Second, we attempt to evaluate whether the likelihood of Italian mothers' leaving or losing their jobs and the factors affecting these probabilities changed between 2005 and 2012.

\section{Background Literature}

TFRs in European countries have declined dramatically in recent decades, falling from an average of 2.3 children per woman in 1970 to 1.6 in 2017. However, the pace and the intensity of this decline varies widely across different institutional settings, with Southern European countries experiencing slower changes but greater losses than Northern European nations. For instance, the term "lowest-low fertility" was introduced by Kohler and colleagues (2001) to describe the dramatic TFR drops to below 1.3 first experienced in Italy and Spain in 1992. When the fall in TFRs became evident, scholars saw a direct link between fertility declines in Western countries and the growth in women's labour market participation (e.g. Brewster \& Rindfuss, 2000). However, starting from the end of the 1980s, a positive cross-country correlation has been observed between TFRs and female labour force participation levels in OECD countries (see, among others, Ahn and Mira, 2002). One key reason proposed to explain this correlation is the importance of both social norms and institutional settings that favour combining work and family tasks. Institutions and policies oriented towards the reconciliation of work and family, such as parental leave, childcare provision, and access to part-time employment, have been shown to be much less widespread in Southern European lowest-low fertility countries (e.g. Del Boca at al., 2009). Moreover, tensions between fertility and women's work have been shown to be more pronounced in countries strongly attached to Catholic values (Matysiak \& Vignoli, 2013). The existence of a strong work-family conflict in Italy appears to be confirmed by the distance between ideal and realized family size: not only does Italy show one of the largest positive discrepancies between desired and actual fertility, but it is also the only European country where women aged 25-39 years reported a higher intended number of children than actual children. This gap is particularly large among highly educated women, who generally show lower actual fertility levels but higher intentions than less-educated women (Testa, 2012).

Differences among institutional settings in the degree of conciliation between family and work are also reflected in mothers' labour market participation levels. According to the latest OECD data available ${ }^{1}$, an average of $66.2 \%$ of mothers with dependent children (aged 0-14) are employed, but countries still show large variations in this regard: six report maternal employment rates above 75\% (with Sweden and Denmark exceeding 80\%), whereas in eight other OECD countries, including Italy (55.3\%), employment rates for mothers with children aged 0-14 are below 60\% (OECD Family Database, www.oecd.org/els/family/database.htm). The decision and timing of parents to (re-)enter the workplace after childbirth can be influenced by many different factors, including individual preferences regarding work, the duration of paid child-related leave schemes, the availability of informal childcare, the availability and cost of formal childcare, the earnings of spouses, and workplace support for parents (OECD, 2011). In a comparative European study of the influence of statutory leave characteristics on the probability of mothers' returning to work at different ages of the child, Pronzato (2009) found that longer periods of job protection increase the hazard of returning to work, while providing paid leave increases the probability of remaining at home during the first year of the child's life. According to the author, women with more human capital go back to work more quickly after childbearing, whereas those with higher family incomes return at a slower rate. The impact of human capital characteristics appears to be relatively larger in Southern European countries like Italy, Spain and Greece, with highly educated women having higher probabilities of returning to work after childbirth. Differences among women with different levels of human capital scarcely exist in countries such as Finland and Austria, which mandate long periods of paid leave. Furthermore, household composition and partners' characteristics play a crucial role in mothers' employment choices (Begall \& Gnunow, 2015). Recent studies have also analysed the controversial impact of housing relocation (Kley \& Drobnic, 2019).

Del Boca and colleagues (2005a) identify difficulties in accessing formal childcare for children under three as a main obstacle for Italian women in combining work and family. According to the authors, Italian public childcare for children under three is both limited and heterogeneous: its availability and cost depend on the characteristics of the household, especially its size, composition, and income. Formal childcare is considerably more widespread in the north (where women's employment is more common) than the south (where women participate less in the labour market). On the

\footnotetext{
${ }^{1}$ Data for Denmark and Finland refer to 2012, data for Chile, Germany, and Turkey to 2013, and data for all other countries refer to 2014.
} 
other hand, private childcare in Italy is neither a substitute for nor a viable alternative to the public service; it shares similar characteristics, so mothers of toddlers tend to rely more heavily on informal care. Overall, then, combining family and work responsibilities may be particularly difficult for Italian mothers of children aged under three years. This is especially true considering that there is ample evidence that the magnitude of unpaid family work is greatest for parents of young children. For example, Apps and Rees (2005) demonstrate that, upon the arrival of a child, male unpaid domestic work more than doubles, while female unpaid domestic work more than triples. Moreover, the load of unpaid domestic work is heavier for Italian than for other European women due to the low contributions of Italian men to household and family care activities (e.g. Zannella et al., 2018).

In recent years, the emergence of the economic crisis in European countries has attracted new interest in the relation between employment conditions and fertility. At the macro level, studies have analysed the connections between TFRs and indicators of economic uncertainty (e.g. Sobotka et al.2011; Comolli, 2017; Goldstein et al, 2013). Those studies' findings have highlighted the existence of a negative relation between the recessionary period and fertility levels. Indeed, according to Matysiak, Sobotka, and Vignoli (2018), TFRs started to increase around the turn of the century and peaked in 2008-2010, after which fertility declined or levelled off in most European countries, especially among young women aged 25 years or less. The fertility decline has been more pronounced in countries and regions that experienced stronger economic downturns and faster increases in unemployment, especially in Southern Europe (Lanzieri, 2013). At the micro level, Comolli and Bernardi (2015) find a positive effect of the recession on childlessness among American women in their late thirties. A later study reported a different situation in Italy, where an acceleration in childlessness rates during the Great Recession was found only among moderately educated Italian women (Caltabiano, Comolli, \& Rosina, 2017). Testa and Basten (2014) demonstrate that the perceived worsening in a household's financial situation during the crisis increased fertility uncertainty for childless people and reduced the number of additionally intended children among those with one child. Similarly, Fiori and colleagues (2018) offer empirical evidence that the economic crisis negatively affected fertility intentions among Italian primiparous mothers, among whom economic constraints represented the main reason for intending not to have another child.

Literature on the relation between fertility and employment has examined the effects of employment, or recently employment uncertainty, on fertility intentions and outcomes; relatively little research, however, has been carried out on the other side of the fertility-employment relation by studying the employment's patterns of women after childbearing. Del Boca and colleagues (2005a) analysed the characteristics of the childcare system in Italy and its relationship to mothers' labour market participation decisions. A study of fertility and female labour force participation in Italy, France, and the UK shows that differences in part-time opportunities are an important explanation of the comparatively low employment rate of Italian women (Del Boca et al., 2005b). The study also demonstrates that the presence of grandparents has a positive effect on women's labour market participation. Matysiak and Vignoli (2013) analysed the probability of women's (re)-entering employment after the first birth in two Catholic countries: Italy and Poland. Their results highlight a relatively rapid employment re-entry of Italian mothers, driven by that country's rather modest parental leave provisions. The authors also stress the existence of a clear conflict between employment and fertility in Italy.

This article expands on previous literature on mothers' employment patterns in two main directions. First, in addition to analysing the probability of women's (re-)entering employment after childbearing, we distinguish among voluntary and involuntary reasons for not returning to work (i.e. mothers who left and who lost their jobs). Second, we develop our analysis for two different years before and after the onset of the economic recession (2005 and 2012, respectively). The specific aim is to evaluate whether the probabilities of leaving or losing a job and the factors affecting these probabilities changed during the period under consideration.

\section{Data and Methods}

This study builds on micro-data from the Birth Sample Survey (BBS) for years 2005 and 2012. The interviews to the mothers were carried out using the C.A.T.I (Computer Assisted Telephone Interview) technique. The samples were respectively 15,870 interviews in 2005 and 17,719 interviews in 2012. The sample is stratified by regions and mothers' age and produces representative estimates at national and macro-areas level. Mothers were interviewed 18 to 24 months after childbearing; a crucial period in which women are generally in the process of reflecting and deciding about having additional children and in which work or financial constraints are more heavily felt. The BBS collects the main socio-demographic information on the newborn, the parents and the delivery as well as information on the mothers' working conditions before and after childbearing, the household composition, the formal and informal childcare networks and the division of household chores. Thus, it represents a precious source of information for studying important aspects as the interaction between maternity and women's participation in the labour market, compatibility between family and work, the lack of facilities for children. 
A first look at the characteristics of the mothers, shows that about $63 \%$ of women were employed during pregnancy in 2005 and $65 \%$ in 2012 (Table 1). Among women who were not working, the number of those looking for a job increased between the two years passing from 3.2\% in 2005 to $5.4 \%$ in 2012 . On the other side, the number of housemakers declined by about 4.4 percentage points (p.p.) during the considered period (from $31.0 \%$ in 2005 to $26.6 \%$ in 2012). In both years the majority of women who worked during pregnancy were employees, whereas self-employed women represented about $11 \%$ of the reference population in 2005 and $9 \%$ in 2012.

Table 1. Women's occupational status during pregnancy (weighted sample estimates)

\begin{tabular}{|c|c|c|c|c|}
\hline & \multicolumn{2}{|l|}{ Year 2005} & \multicolumn{2}{|l|}{ Year 2012} \\
\hline & $\mathbf{N}$ & $\%$ & $\mathbf{N}$ & $\%$ \\
\hline Total & 531,161 & 100.0 & 534,203 & 100.0 \\
\hline Employed & 334,306 & 63.0 & 345,857 & 64.7 \\
\hline Employees & 263,918 & 49.7 & 281,177 & 52.6 \\
\hline Self-employed & 57,207 & 10.8 & 47,805 & 8.9 \\
\hline Other & 13,181 & 2.5 & 16,875 & 3.2 \\
\hline Not employed & 196,855 & 37.0 & 188,346 & 35.2 \\
\hline Searching for a job & 17,256 & 3.2 & 28,869 & 5.4 \\
\hline Housemakers & 164,845 & 31.0 & 141,771 & 26.6 \\
\hline Other & 14,754 & 2.8 & 17,706 & 3.3 \\
\hline
\end{tabular}

About $82 \%$ of women employed during pregnancy were still employed at the interview in 2005, whereas the number decreased to approximately $77 \%$ in 2012 (Table 2). Among women who did not return to work, about $4 \%$ were searching for a job 18-24 months after the birth of the child, 14\% were housemakers and $1 \%$ were in other status (e.g. students, retired, etc.). The data show a different situation in 2012: about $8 \%$ of employed women who did not go back to work after childbearing were searching for a job, $13 \%$ left the labour market to become housemakers and $2 \%$ were in other status. About $30 \%$ of those searching for a job during pregnancy were employed at the interview in 2005 while the number declined to $21 \%$ in 2012 , which is also reflected by a higher number of women changing their occupational status from job searching to housemaker in the latter year compared to the former (29\% and 16\%, respectively). In 2005, $89 \%$ of housemakers did not change their status after childbearing while the probability of permanence was lower in $2012(86 \%)$ with a higher share of housemakers searching for a job (about 7\% compared to 3.5\% in 2005).

Table 2. Transition matrix by employment status and survey year (weighted sample estimates)

\begin{tabular}{|c|c|c|c|c|c|c|}
\hline \multirow[b]{2}{*}{ Pregnancy } & \multicolumn{5}{|c|}{ Year 2005} & \multirow[b]{2}{*}{$\mathrm{N}$} \\
\hline & Employed & $\begin{array}{l}\text { Searching for } \\
\text { a job }\end{array}$ & Housemaker & Other & Total & \\
\hline Employed & 81.6 & 4.1 & 13.6 & 0.7 & 100.0 & 334,306 \\
\hline Job searching & 29.7 & 53.4 & 15.9 & 0.9 & 100.0 & 17,256 \\
\hline Housemakers & 7.1 & 3.5 & 88.8 & 0.6 & 100.0 & 164,845 \\
\hline Other & 25.1 & 12.1 & 24.7 & 38.1 & 100.0 & 14,754 \\
\hline \multirow[t]{2}{*}{ Total } & 55.2 & 5.7 & 37.4 & 1.7 & 100.0 & 531,161 \\
\hline & \multicolumn{5}{|c|}{ Year 2012} & \multirow[b]{2}{*}{$\mathrm{N}$} \\
\hline Pregnancy & Employed & $\begin{array}{c}\text { Searching for } \\
\text { a job }\end{array}$ & Housemaker & Other & Total & \\
\hline Employed & 77.3 & 7.8 & 12.9 & 2.0 & 100.0 & 345,857 \\
\hline Job searching & 21.1 & 47.3 & 29.1 & 2.5 & 100.0 & 28,869 \\
\hline Housemakers & 6.5 & 6.8 & 86.1 & 0.6 & 100.0 & 141,771 \\
\hline Other & 22.9 & 21.8 & 24 & 31.3 & 100.0 & 17,706 \\
\hline Total & 53.7 & 10.1 & 33.6 & 2.6 & 100.0 & 534,203 \\
\hline
\end{tabular}

The goal of this article is to estimate the probability of Italian women's not returning to work in the 18-24 months 
following childbirth, distinguishing between voluntary and involuntary reasons for the employment discontinuity (i.e. the mother lost/left the job). To this end, we focus on women who had a dependent job during pregnancy (with a sample size of 8,113 in 2005 and 10,121 in 2012). Our choice is motivated by two main reasons. First, they are the great majority of employed women (about $80 \%$ of total employed women during pregnancy in both years). Second, for the purposes of this article, employee women represent a more homogenous group to study. For instance, the distinction between losing/leaving the job can be somehow blurred for self-employed women, while it can be more easily interpreted in the case of dependent work for which losing the job coincides with layoffs.

We run three different logistic models for each of the following dependent variables: the overall probability of mothers' not returning to work, without regard to cause; the probability of mothers' leaving their job; the probability of mothers' losing their jobs. We include the following explanatory variables in the models: survey's year $(2005,2012)$; age group (until 24, 25-29, 30-34, 35-49, 40+); living arrangement (couple, single); educational level (high, medium, low); birth parity (first order, second or higher order); type of contract (public permanent, public fixed-term, private permanent, private fixed-term); occupational level (high, medium, low); geographic area of residence (north, centre, south and islands); partner's occupational level (high, medium, low/unemployed); form of housing tenure (ownership/usufruct, rent and other forms).. We are particularly interested in changes occurred between the survey's years. For this reason, we allow all parameters to differ across years by including an interaction term.

\section{Results}

The probability of employed women not returning to work 18-24 months after childbearing was statistically significantly higher in 2012 compared to 2005. Mothers in the youngest age group (aged 24 years or less) had a significantly higher probability of not returning to work than those in the oldest age group ( 40 years and over), while the relation was less significant for the remaining age groups (see Table 3). Being single, having a high educational or occupational level, living in the north, and owning one's residence were all characteristics of mothers that were negatively associated with the probability of not going back to work. By contrast, a high occupational status of the partner significantly increased this probability. As expected, working in the public sector and having a permanent contract were both protective factors for women's employment continuity. However, women working in the public sector with a fixed-term contract had higher probabilities of not returning to work than those working in the public sector with a permanent position, suggesting that contract duration plays a more relevant role in favouring employment continuity among mothers. Nevertheless, the results shown in Table 3 refer to the overall probability of mothers of becoming unemployed after childbearing, without distinguishing among voluntary and involuntary motivations for not returning to work; this lack of detail can hide very different realities. To shed light on how various factors are related to the different reasons for becoming unemployed, we estimated two additional regression models for the probability of leaving (Table 4) and losing (Table 5) a job after the birth of a child.

The probability of mothers' leaving their jobs was negatively associated with their age, educational level, and occupational level and positively associated with the birth's parity. Single mothers had significantly lower probabilities of leaving a job than those in a couple, likely a result of greater financial pressures on the former group. Conversely, a partner's high occupational status increased this probability. The geographical area of residence significantly affected the decision of mothers not to return to work, with those leaving in the Northern Italy being less likely to leave their jobs than those living in the Central, Southern, and Islands areas. Women with permanent contracts in the public sector during pregnancy were less likely to leave a job than those employed in the private sector or those with temporary contracts. The results for the simple effect of year on the probability of mothers' leaving a job were not statistically significant, suggesting that the decision not to return to work depends more on individuals' and couples' preferences rather than on exogenous contextual factors. Consistent with this finding, the results of the model's interactive effects highlight a fairly stable relation of the covariates with the probability of mothers' leaving a job in the two years following the birth of a child.

Looking at the simple effects of the model on the probability of losing a job in Table 5 reveals a different situation. In fact, the likelihood of mothers' losing a job increased significantly in 2012 over 2005, likely as a result of the deterioration of labour market conditions during the recession years. A statistically significant effect of the age group on the likelihood of losing the job is found only in 2012 when, contrary to our expectations, young mothers were less likely to experience job loss. This result is explained by a corresponding increase in the probability of young mothers' leaving their job, which in turn may depend on the combined effect of their lower occupational status and their better opportunities to find a new job in the future. Mothers living in the north had significantly lower probabilities of being dismissed after childbirth. The results for the form of housing tenure, which we consider an indicator of economic well-being, indicate that ownership status had a significantly negative effect compared to those who were renting. Having high educational and occupational levels significantly lowers the likelihood of dismissal. As expected, being employed in the public sector with an open-ended contract significantly reduces the likelihood of losing one's job. In 
addition, among women employed in the public sector, those with fixed-term contracts had significantly higher possibilities of losing their jobs after childbirth, suggesting that contract duration was the most important job characteristic for continued or discontinued employment among mothers. On the other hand, family characteristics related to the presence of a couple and the partner's job characteristics were not significantly associated with the probability of mothers' losing their jobs.

Table 3. Model estimates of the probability of employee women of not returning to work 18-24 months after childbirth

\begin{tabular}{|c|c|c|c|c|c|c|c|c|c|}
\hline & \multirow{2}{*}{\multicolumn{3}{|c|}{ Simple effects }} & \multicolumn{6}{|c|}{ Interactive effects } \\
\hline & & & & \multicolumn{3}{|c|}{2005} & \multicolumn{3}{|c|}{2012} \\
\hline & $\begin{array}{l}\text { Odds } \\
\text { ratio }\end{array}$ & $\begin{array}{c}\text { Standard } \\
\text { Error }\end{array}$ & $\begin{array}{c}\text { Prob > } \\
\text { Chi-Square }\end{array}$ & $\begin{array}{l}\text { Odds } \\
\text { ratio }\end{array}$ & $\begin{array}{c}\text { Standard } \\
\text { Error }\end{array}$ & $\begin{array}{c}\text { Prob > } \\
\text { Chi-Square }\end{array}$ & $\begin{array}{l}\text { Odds } \\
\text { ratio }\end{array}$ & $\begin{array}{c}\text { Standard } \\
\text { Error }\end{array}$ & $\begin{array}{c}\text { Prob > } \\
\text { Chi-Square }\end{array}$ \\
\hline Year $(\operatorname{Ref}=2005)$ & 2.103 & 0.360 & $<0.001$ & & & & & & \\
\hline \multicolumn{10}{|l|}{ Age $(\operatorname{Ref}=40+)$} \\
\hline Until 24 & 2.102 & 0.291 & $<0.001$ & 2.114 & 0.477 & 0.001 & 2.090 & 0.315 & $<0.001$ \\
\hline $25-29$ & 1.416 & 0.167 & 0.003 & 1.591 & 0.328 & 0.024 & 1.260 & 0.134 & 0.030 \\
\hline $30-34$ & 1.194 & 0.135 & 0.115 & 1.264 & 0.255 & 0.247 & 1.128 & 0.103 & 0.185 \\
\hline $35-39$ & 1.124 & 0.130 & 0.313 & 1.181 & 0.247 & 0.426 & 1.070 & 0.096 & 0.456 \\
\hline \multicolumn{10}{|c|}{ Living arrangement $(\mathrm{Ref}=$ Couple $)$} \\
\hline Single & 0.535 & 0.065 & $<0.001$ & 0.490 & 0.101 & 0.001 & 0.584 & 0.076 & $<0.001$ \\
\hline \multicolumn{10}{|c|}{ Educational level $\quad(\operatorname{Ref}=\mathrm{High})$} \\
\hline Medium & 1.735 & 0.113 & $<0.001$ & 1.732 & 0.179 & $<0.001$ & 1.737 & 0.136 & $<0.001$ \\
\hline Low & 2.339 & 0.179 & $<0.001$ & 2.864 & 0.350 & $<0.001$ & 1.910 & 0.177 & $<0.001$ \\
\hline \multicolumn{10}{|l|}{ Parity $\quad(\operatorname{Ref}=$ First birth $)$} \\
\hline Second birth or higher birth & 0.987 & 0.044 & 0.767 & 1.025 & 0.072 & 0.728 & 0.950 & 0.054 & 0.365 \\
\hline \multicolumn{10}{|c|}{ Job characteristics (Ref = Public permanent) } \\
\hline Public fixed-term & 3.405 & 0.371 & $<0.001$ & 3.334 & 0.572 & $<0.001$ & 3.478 & 0.468 & $<0.001$ \\
\hline Private permanent & 2.675 & 0.211 & $<0.001$ & 3.812 & 0.484 & $<0.001$ & 1.877 & 0.177 & $<0.001$ \\
\hline Private fixed-term & 9.249 & 0.835 & $<0.001$ & 11.479 & 1.684 & $<0.001$ & 7.452 & 0.785 & $<0.001$ \\
\hline \multicolumn{10}{|c|}{ Occupational level $($ Ref $=$ High $)$} \\
\hline Medium & 2.414 & 0.409 & $<0.001$ & 2.837 & 0.777 & $<0.001$ & 2.055 & 0.409 & $<0.001$ \\
\hline Low & 4.289 & 0.749 & $<0.001$ & 4.954 & 1.396 & $<0.001$ & 3.713 & 0.766 & $<0.001$ \\
\hline \multicolumn{10}{|c|}{ Geographic area $\quad($ Ref $=$ North $)$} \\
\hline Centre & 1.276 & 0.068 & $<0.001$ & 1.234 & 0.103 & 0.012 & 1.320 & 0.088 & $<0.001$ \\
\hline South and islands & 1.672 & 0.083 & $<0.001$ & 1.562 & 0.121 & $<0.001$ & 1.790 & 0.112 & $<0.001$ \\
\hline \multicolumn{10}{|c|}{ Partner's occupational cond. $($ Ref = High $)$} \\
\hline Medium & 0.826 & 0.048 & 0.001 & 0.728 & 0.065 & $<0.001$ & 0.938 & 0.070 & 0.389 \\
\hline Low & 0.690 & 0.044 & $<0.001$ & 0.565 & 0.056 & $<0.001$ & 0.842 & 0.068 & 0.032 \\
\hline \multicolumn{10}{|c|}{ Form of housing tenure (Ref = Own./usufr.) } \\
\hline Rent and other forms & 1.274 & 0.064 & $<0.001$ & 1.398 & 0.108 & $<0.001$ & 1.161 & 0.075 & 0.021 \\
\hline
\end{tabular}


Table 4. Model estimates of the probability of employee women of leaving the job 18-24 months after childbirth

\begin{tabular}{|c|c|c|c|c|c|c|c|c|c|}
\hline & \multirow{2}{*}{\multicolumn{3}{|c|}{ Simple effects }} & \multicolumn{6}{|c|}{ Interactive effects } \\
\hline & & & & & 2005 & & 2012 & & \\
\hline & $\begin{array}{l}\text { Odds } \\
\text { ratio }\end{array}$ & $\begin{array}{c}\text { Standard } \\
\text { Error }\end{array}$ & $\begin{array}{c}\text { Prob > } \\
\text { Chi-Square }\end{array}$ & $\begin{array}{l}\text { Odds } \\
\text { ratio }\end{array}$ & $\begin{array}{c}\text { Standard } \\
\text { Error }\end{array}$ & $\begin{array}{c}\text { Prob > } \\
\text { Chi-Square }\end{array}$ & $\begin{array}{l}\text { Odds } \\
\text { ratio }\end{array}$ & $\begin{array}{c}\text { Standard } \\
\text { Error }\end{array}$ & $\begin{array}{c}\text { Prob > } \\
\text { Chi-Square }\end{array}$ \\
\hline Year $(\operatorname{Ref}=2005)$ & 1.522 & 0.343 & 0.063 & & & & & & \\
\hline \multicolumn{10}{|l|}{ Age $(\operatorname{Ref}=40+)$} \\
\hline Until 24 & 3.030 & 0.477 & $<0.001$ & 2.129 & 0.548 & 0.003 & 4.313 & 0.782 & $<0.001$ \\
\hline $25-29$ & 1.935 & 0.268 & $<0.001$ & 1.586 & 0.375 & 0.051 & 2.361 & 0.343 & $<0.001$ \\
\hline $30-34$ & 1.465 & 0.195 & 0.004 & 1.148 & 0.266 & 0.553 & 1.871 & 0.242 & $<0.001$ \\
\hline $35-39$ & 1.357 & 0.185 & 0.025 & 1.207 & 0.288 & 0.431 & 1.527 & 0.198 & 0.001 \\
\hline \multicolumn{10}{|c|}{ Living arrangement $(\operatorname{Ref}=$ Couple $)$} \\
\hline Single & 0.356 & 0.061 & $<0.001$ & 0.319 & 0.091 & $<0.001$ & 0.397 & 0.078 & $<0.001$ \\
\hline \multicolumn{10}{|c|}{ Educational level $\quad($ Ref $=$ High $)$} \\
\hline Medium & 1.802 & 0.151 & $<0.001$ & 1.716 & 0.218 & $<0.001$ & 1.891 & 0.207 & $<0.001$ \\
\hline Low & 2.724 & 0.261 & $<0.001$ & 3.199 & 0.466 & $<0.001$ & 2.319 & 0.288 & $<0.001$ \\
\hline \multicolumn{10}{|l|}{ Parity $\quad(\operatorname{Ref}=$ First birth $)$} \\
\hline Second birth or higher birth & 1.206 & 0.065 & 0.001 & 1.181 & 0.096 & 0.040 & 1.232 & 0.088 & 0.004 \\
\hline \multicolumn{10}{|c|}{ Job characteristics $(\operatorname{Ref}=$ Public permanent $)$} \\
\hline Public fixed-term & 1.474 & 0.221 & 0.010 & 1.626 & 0.376 & 0.035 & 1.337 & 0.256 & 0.130 \\
\hline Private permanent & 2.324 & 0.219 & $<0.001$ & 3.504 & 0.516 & $<0.001$ & 1.541 & 0.181 & $<0.001$ \\
\hline Private fixed-term & 4.518 & 0.482 & $<0.001$ & 7.610 & 1.284 & $<0.001$ & 2.682 & 0.351 & $<0.001$ \\
\hline \multicolumn{10}{|c|}{ Occupational level (Ref = High) } \\
\hline Medium & 1.782 & 0.361 & 0.004 & 2.274 & 0.714 & 0.009 & 1.397 & 0.357 & 0.191 \\
\hline Low & 2.976 & 0.621 & $<0.001$ & 3.956 & 1.279 & $<0.001$ & 2.238 & 0.591 & 0.002 \\
\hline \multicolumn{10}{|c|}{ Geographic area $(\operatorname{Ref}=$ North $)$} \\
\hline Centre & 1.255 & 0.081 & $<0.001$ & 1.292 & 0.123 & 0.007 & 1.219 & 0.105 & 0.022 \\
\hline South and islands & 1.588 & 0.094 & $<0.001$ & 1.439 & 0.130 & $<0.001$ & 1.752 & 0.135 & $<0.001$ \\
\hline \multicolumn{10}{|c|}{ Partner's occupational cond. $($ Ref = High) } \\
\hline Medium & 0.796 & 0.055 & 0.001 & 0.724 & 0.074 & 0.001 & 0.876 & 0.082 & 0.157 \\
\hline Low & 0.591 & 0.045 & $<0.001$ & 0.486 & 0.055 & $<0.001$ & 0.719 & 0.072 & 0.001 \\
\hline \multicolumn{10}{|c|}{ Form of housing tenure (Ref = Own./usufr.) } \\
\hline Rent and other forms & 1.150 & 0.070 & 0.021 & 1.266 & 0.114 & 0.009 & 1.044 & 0.085 & 0.593 \\
\hline
\end{tabular}


Table 5. Model estimates of the probability of employee women of losing the job 18-24 months after childbirth

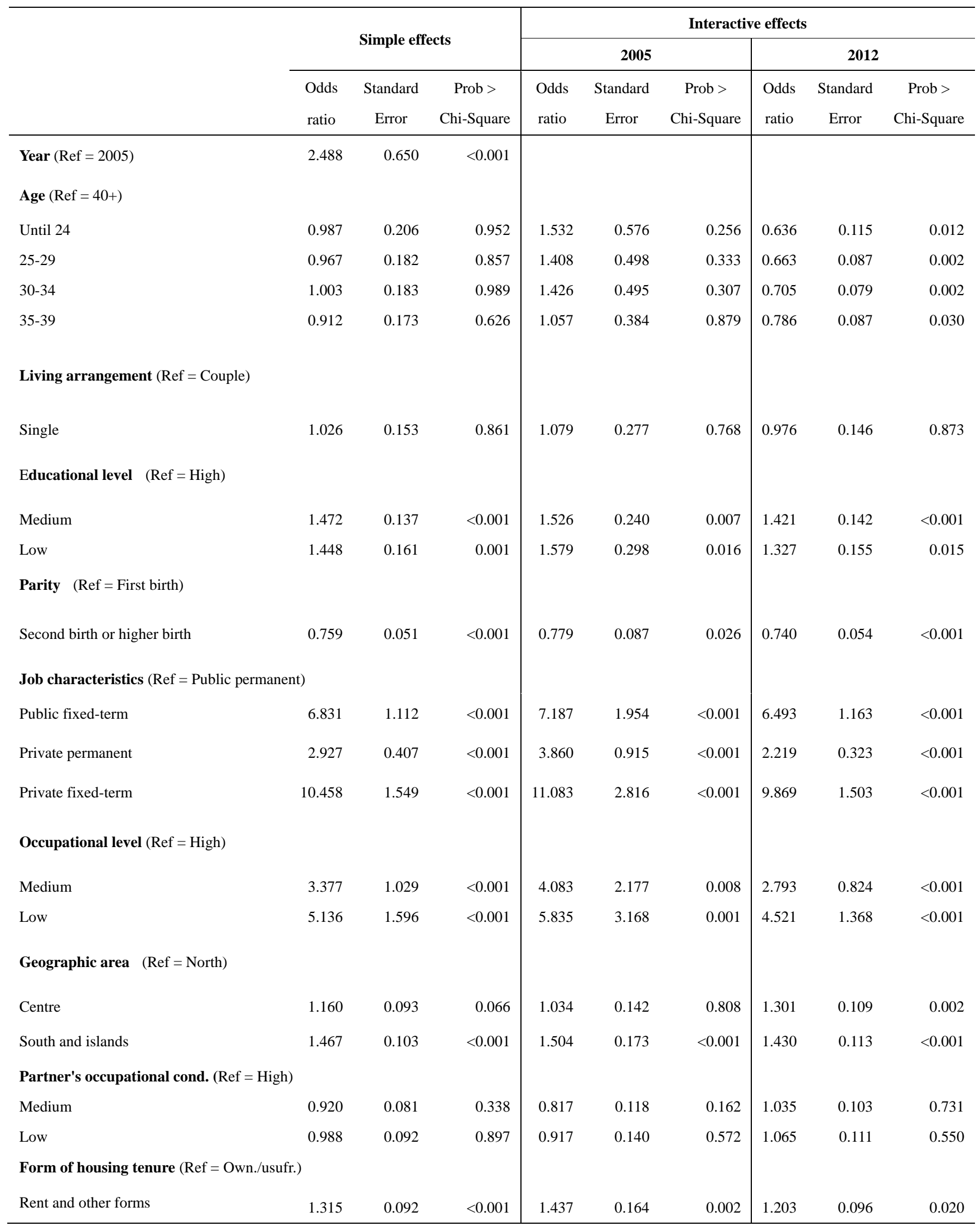




\section{Discussion and Conclusions}

This study has aimed to broaden the understanding of individual and contextual characteristics that can affect discontinuity in the employment paths of mothers of young children. The probability of employee mothers' not returning to work in the 18-24 months following childbirth rose significantly in 2012 over 2005 . This increase is explained by the growing probability of losing a job between 2005 and 2012 and suggests a negative role played by the economic downturn on the employment continuity of mothers.

The characteristics of work are among the key determinants of employment continuity or discontinuity in the two years after the birth of a child: a protective role is played by the public sector, especially by open-ended contracts. In 2005 , the mother's occupational level and type of contract were among the most important factors affecting the probability of losing a job. By 2012, however, the magnitude of those effects declined, highlighting the existence of a universal trend in increasing risk of job loss. This aspect may be explained by the powerful effects of economic recession on labour market participation in Italy where, according to Eurostat data, the employment rate dropped from $62.9 \%$ in 2008 to $60.9 \%$ in 2012.

Single mothers were less likely than their counterparts to leave work after childbirth, probably due to their having limited resources available to finance periods away from jobs. Housing tenure was also an important factor to take into account. When mothers (or other household members) are the owners of their residences, they show lower probabilities of losing or leaving a job. As Kley and Drobnic (2019) also note, housing relocation and women's employment conditions are closely intertwined. Moreover, in the Italian context where becoming owner of a home (even with a mortgage) is widely pursued, ownership may be considered both a proxy for socio-economic status and a possible indicator of taking root in a specific area.

Han and colleagues (2008) found American mothers with three or more children to be less likely to work in the years following a birth than primiparous mothers. Our regression results for the probability of leaving a job confirm this finding. By contrast, the probability of layoffs was lower for mothers of a second (or higher) birth order. More generally and consistent with that study, we found that women with greater family's resources, i.e. those in a couple, with a partner with a high occupational status, were more likely to leave a job in the two years following childbirth.

Contextual variables suggest other useful indications for policy implementation. Mothers resident in Southern areas showed significantly higher probabilities of losing and leaving their jobs. In fact, childcare services supply is not even a valid option in the South of Italy, in terms of either availability or affordability. These considerations were made more relevant by the severe social and economic consequences of the recent economic crisis. According to Crepaldi and colleagues (2014), the recent recession has aggravated the pre-existing structural weakness of the Italian labour market, leading to the marginalization of specific segments of the working population, notably women and young people, and especially those residing in Southern regions. Therefore, although the gender gap in employment declined considerably after 2008 as an effect of the greater disadvantages experienced by men during the economic crisis, women in Italy are still among the most vulnerable segments of the population. Not only is female labour market participation still considerably lower than in other European countries, but the Great Recession has also intensified occupational gender segregation, with women reporting a higher incidence of low-qualified jobs and atypical contracts, lower probabilities of transition into permanent contracts, and lower wages than men. Improving the understanding of the factors that may facilitate the reconciliation between family and work is of vital importance for today's societies - and particularly for Italy - to reduce the risk of poverty for individuals and families. In 2017, for instance, 29\% of the population was considered at risk of poverty and social exclusion in Italy, compared to the EU-28 average of $22 \%$. The figure grows to $31.5 \%$ for Italian children younger than $16(24.4 \%$ at the EU-28 level) with one of the largest increases among European countries recorded since 2010 (about 2.6\%) (Eurostat database, Population, Income and Living Conditions). Achieving work-life balance is a difficult goal, but a number of measures have been shown to be effective in helping people reconcile work and family life, including employment-protected leave for parents, flexibility in the organization of work (part-time work, flexible working time, and telework), and the availability of affordable public childcare services. Such measures are made more essential by the existing context of a rapidly aging population in which promoting higher levels of both fertility and female labour force participation are key factors in ensuring the long-term sustainability of welfare states.

\section{References}

Ahn, N., \& Mira, P. (2002). A note on the changing relationship between fertility and female employment rates in developed countries. Journal of population Economics, 15(4), 667-682. https://doi.org/10.1007/s001480100078 
Anxo, D., Mencarini, L., Pailhé, A., Solaz, A., Tanturri, M. L., \& Flood, L. (2011). Gender differences in time use over the life course in France, Italy, Sweden, and the US. Feminist Economics, 17(3), 159-195. https://doi.org/10.1080/13545701.2011.582822

Apps, P., \& Rees, R. (2005). Gender, time use, and public policy over the life cycle. Oxford Review of Economic Policy 21(3), 439-461. https://doi.org/10.1093/oxrep/gri025

Begall, K., \& Grunow, D. (2015). Labour force transitions around first childbirth in the Netherlands. European Sociological Review, 31(6), 697-712. https://doi.org/10.1093/esr/jcv068

Brewster, K. L., \& Rindfuss, R. R. (2000). Fertility and women's employment in industrialized nations. Annual Review of Sociology, 26(1), 271-296. https://doi.org/10.1146/annurev.soc.26.1.271

Caltabiano, M., Comolli, C. L., \& Rosina, A. (2017). The effect of the Great Recession on permanent childlessness in Italy. Demographic Research, 37, 635-668. https://doi.org/10.4054/DemRes.2017.37.20

Comolli, C. L. (2017). The fertility response to the Great Recession in Europe and the United States: Structural economic conditions and perceived economic uncertainty. Demographic Research, 36(51), 1549-1600. https://doi.org/10.4054/DemRes.2017.36.51

Del Boca, D., Locatelli, M., \& Vuri, D. (2005a). Child-care choices by working mothers: The case of Italy. Review of Economics of the Household, 3(4), 453-477. https://doi.org/10.1007/s11150-005-4944-y

Del Boca, D., Pasqua, S., \& Pronzato, C. (2005b). Fertility and employment in Italy, France, and the UK. Labour 19: 51-77. https://doi.org/10.1111/j.1467-9914.2005.00323.x

Del Boca, D., Pasqua, S., \& Pronzato, C. (2009). Motherhood and market work decisions in institutional context: a European perspective. Oxford Economic Papers, 61, 147-171. https://doi.org/10.1093/oep/gpn046

Fiori, F., Graham, E., \& Rinesi, F. (2018). Economic reasons for not wanting a second child: Changes before and after the onset of the economic recession in Italy. Demographic research, 38, 843-854. https://doi.org/10.4054/DemRes.2018.38.30

Goldstein, J. R., Kreyenfeld, M., Jasilioniene, A., \& Karaman, Ö. D. (2013). Fertility reactions to the 'Great Recession' in Europe: Recent evidence from order-specific data. Demographic Research, 29(4), 85-104. https://doi.org/10.4054/DemRes.2013.29.4

Han, W. J., Ruhm, C. J., Waldfogel, J., \& Washbrook, E. (2008). The timing of mothers' employment after childbirth. Monthly labor review/US Department of Labor, Bureau of Labor Statistics, 131(6), 6-15.

Kley, S., \& Drobnič, S. (2019). Does moving for family nest-building inhibit mothers' labour force (re-)entry? Demographic Research, 40(7), 155-184. https://doi.org/10.4054/DemRes.2019.40.7

Kohler, H. P., Ortega, J. A., \& Billari, F. C. (2001). Towards a theory of lowest-low fertility (No. WP-2001-032). Max Planck Institute for Demographic Research, Rostock, Germany.

Lanzieri, G. (2013). Towards a 'baby recession' in Europe? Differential fertility trends during the economic crisis. Luxembourg: Eurostat (Statistics in focus 13-2013).

Matysiak, A., \& Vignoli, D. (2008). Fertility and women's employment: A meta-analysis. European Journal of Population/Revue européenne de Démographie, 24(4), 363-384. https://doi.org/10.1007/s10680-007-9146-2

Matysiak, A., \& Vignoli, D. (2013). Diverse effects of women's employment on fertility: Insights from Italy and Poland. European Journal of Population/Revue européenne de Démographie, 29(3), 273-302. https://doi.org/10.1007/s10680-013-9287-4

Matysiak, A., Vignoli, D., \& Sobotka, T. (2018). The Great Recession and fertility in Europe: A sub-national analysis. Vienna Institute of Demography Working Papers 2/2018

OECD (2006). Live Longer, Work Longer, OECD Publishing, Paris.

OECD (2011). Doing Better for Families. OECD Publishing. https://doi.org/10.1787/9789264098732-en

Pronzato, C. D. (2009). Return to work after childbirth: does parental leave matter in Europe?. Review of Economics of the Household, 7(4), 341-360. https://doi.org/10.1007/s11150-009-9059-4 
Sobotka, T., Skirbekk, V., \& Philipov, S. (2011). Economic recession and fertility in the developed world. Population and Development Review, 37(2), 267-306. https://doi.org/10.1111/j.1728-4457.2011.00411.x

Testa, M. R. (2012). Family sizes in Europe: Evidence from the 2011 Eurobarometer survey. European Demographic Research Paper N. 2. Vienna Institute of Demography, Austrian Academy of Sciences

Testa, M. R., \& Basten, S. (2014). Certainty of meeting fertility intentions declines in Europe during the Great Recession'. Demographic Research, 31(23), 687-734. https://doi.org/10.4054/DemRes.2014.31.23

\section{Copyrights}

Copyright for this article is retained by the author(s), with first publication rights granted to the journal.

This is an open-access article distributed under the terms and conditions of the Creative Commons Attribution license (http://creativecommons.org/licenses/by/4.0/). 